\title{
Strategi Komunikasi Radio Fajri 993 FM Bogor dalam Mempertahankan Citra Radio Dakwah
}

\author{
Neisya Ghassani Sabilah ${ }^{\mathbf{1}}$, Armawati Arbi ${ }^{\mathbf{2}}$ \\ ${ }^{1}$ Universitas Islam Negeri (UIN) Syarif Hidayatullah Jakarta ; \\ ${ }^{2}$ Fakultas Ilmu Dakwah dan Ilmu Komunikasi, Universitas Islam Negeri (UIN) \\ Syarif Hidayatullah Jakarta \\ e-mail: $\underline{{ }^{1} \text { neisyaghassani@gmail.com }}, \underline{{ }^{2} \text { armawati.arbi@uinjkt.ac.id }}$
}

\begin{abstract}
Islam or dakwah radio usually include community radio that is AM network,how ever, Fajri radio is 99.3 FM in Bogor that can stand for the Islamic program as commercial radio. Fajri Radio is In the development of ITC (information technology communication), the radio can develop its identity as dakwah radio. How has Fajri radio exitied to become Dakwah radio without a music program?The theory of mass social media construction on social reality (Burhan Bungin, 2007) can answer how construct a program through three processes; externalization, objectivation, and internalization to develop current image. This study uses a qualitative method with a constructivism paradigm. The methods conducted through text analysis, active observation, and participation. The results of the research found 1) the externalization is to express identity, ideas, facts, references as framing strategy planning of rundown which facts have been edited on, planning run down as priming strategy 2) signing strategy of Fajri 99.3 FM Bogor Radio in maintaining on each segment in the objectivacation through various method of dakwah and communication.Radio Fajri FM has 7 live programs and 32 tapping programs. 3) The internalization modifies air program, off-air program or religious events monthly,modification of program, publications, and Fajri listeners' radio FM has conducted training for senior high school and undergraduated students to modify on air program and off meetings.
\end{abstract}

\section{Keywords: Communication Strategy, Community Radio,Mass Media Social construction, current image}

\begin{abstract}
Abstrak
Radio Islam atau radio dakwah biasanya termasuk radio komunitas dan jaringan AM, akan tetapi, radio Fajri 99,3 masuk pada jaringan FM di Bogor, radionya dapat bertahan dengan program Islamnya sebagai radio komersil. Fajri radio terus mengembangkan ITC (information Tehnology, and
\end{abstract}


communication) menjaga identitas radionya sebagai radio dakwah. Bagaimana radio ini tetap eksis menjadi radio dakwah tanpa program musik? Teori konstruksi sosial media massa atas realitas sosial menjawab bagaimana mengkonstruksi sebuah program melalui tiga proses yakni eksternalisasi, objektivasi, dan internalisasi untuk menyebar informasi, yang disebut current image. Penelitian ini menggunakan metode kualitatif dengan paradigma konstruktivisme. Hasil penelitian ditemukan 1) Tahap esternalisasi adalah menerapkan identitas media melalui ekspresi ide,fakta,dan referensi sebagai strategi komunikasi Framing Radio Fajri 99,3 FM Bogor, 2) Tahap objektivasi dikemas tujuh program live dan 32 program tapping melalui berbagai metode dakwah dan komunikasi. Kekuatan kata dan bahasa pada program tersebut diterapkan strategi signing, dan 3) Tahap internalisasi, radio Fajri FM memodifikasi program on air maupun kegiatan off air berupa kajian bulanan, publikasi, dan temu pendengar Fajri.

\section{Kata-kata Kunci: Strategi Komunikasi, Radio, Konstruksi Sosial Media Massa, current image.}

\section{A. Pendahuluan}

Tingkat persaingan stasiun radio di kota-kota besar dewasa ini cukup tinggi dalam merebut perhatian audiens. Program dakwah di radio komunitas sebaiknya dikemas sedemikian rupa agar menarik perhatian dan dapat diikuti sebanyak mungkin orang (Andi Faisal Bakti, 2010). Radio Fajri cukup berani menerapkan karakter radio dakwah dan berani bergabung pada kelompok radio komersil. di tambah lagi radio ini mengemas dakwah. Dengan demikian, setiap produksi programnya sebaiknya mengacu pada kebutuhan audien yang menjadi target stasiun radio (target audiens).

Perjuangan radio semakin berat karena persaingan media lama dan media baru semakin bertambah seperti new media dan podcast. Survei Nielsen Consumer Media View (survei Nielsen Indonesia 2017) menyebut bahwa penetrasi radio masih menempati urutan keempat dibanding jenis media lain. Televisi masih menjadi media utama bagi masyarakat Indonesia di mana penetrasinya mencapai 96 persen, selanjutnya media luar ruang dengan penetrasi 53 persen, internet 44 persen, dan di posisi ke empat media radio 37 persen. Adapun penetrasi media koran hanya 7 persen serta majalah dan tabloid 3 persen. Solusinya, media saling membantu atau convergent media dengan media lainnya. (konvergensi media) 
Menurut Masduki, dalam menentukan format radio itu dilakukan dengan strategi Segmenting, Targeting, Positioning, Formating dan programming. Strategi dalam format radio itu sendiri dituangkan dalam bentuk susunan program mata acara siaran. Bagaimana semestinya program acara tersebut disusun oleh radio agar banyak audience yang menggemari. Susunan program acara siaran tersebut mesti yang berorientasi pada selera audience sebagai sasaran penerima pesan, guna menyajikan 'sesuatu yang berbeda' dalam berbagai bentuk program kreatif yang tidak dilakukan competitor (Masduki). Sedangkan Ibnu Hamad (2010) menjelaskan tiga startegi komunikasi; Framing, Priming, dan signing. Strategi framing melihat kekuatan fakta, kekuatan tata waktu/tata letak adalah strategi priming, Sedangkan kekuatan kata dan bahasa disebut strategi signing.

Menurut Arsenti, identitas media terdiri dari brand,citra, dan reputasi. (Paul Arsenti, 2007). PT. Radio Fajar Imani atau lebih dikenal dengan sebutan Radio Fajri FM dengan mottonya "Suara Kebangkitan Islam" sebagai brand mencoba menyajikan informasi dan kajian-kajian keagamaan yang bersumber pada dalildalil yang benar dan shohih, mencerdaskan dan memahamkan ummat sehingga kehidupan yang mereka jalani berada pada jalan yang lurus, moral, dan spiritual yang baik. Serta memberikan informasi-informasi edukatif kepada masyarakat luas. Dengan eksistensi radio dakwah Islam Fajri FM yang mempunyai warna dan ciri khas tersendiri yang jarang dimiliki oleh radio-radio FM lainnya yaitu siarannya full time dakwah Islam tanpa musik seperti radio Rodja. Berbeda dengan radio komunitas, radio dakwah 720 AM, yaitu Radio Silaturahim memutar lagu di setiap acaranya untuk menarik pendengar.

Burhan Bungin mendefisikan teori konstruksi sosial media massa atas realitas sosial. Bungin mengkritik karya Berger dan Luckmann. Mereka menulis buku Social Contruction of Reality (1965), mengenai konstruksi sosial atas realitas sosial, yang dibangun secara simultan melalui tiga proses, yaitu eksternalisasi, objektivasi, dan internalisasi. Proses simultan ini terjadi antara individu satu dengan individu lainnya di dalam masyarakat. Bangunan realitas yang tercipta karena proses sosial tersebut adalah realitas objektif, subjektif, dan simbolis atau intersubjektif. Substansi "teori konstruksi media massa" adalah pada sirkulasi 
informasi yang cepat dan luas sehingga konstruksi sosial berlangsung dengan sangat cepat dan sebarannya merata. Dari konten konstruksi sosial media massa, proses kelahiran konstruksi sosial media massa melalui tahap-tahap sebagai berikut: a) tahap menyiapkan materi konstruksi, b) tahap sebaran konstruksi, c) tahap pembentukan konstruksi dan d) tahap konfirmasi. (Bungin, 2011).

Armawati Arbi memperkaya proses konstruksi di atas bahwa konstruksi radio atas realitas berlangsung dalam tiga tahap proses dialektika: yang pertama, tahap eksternalisasi pendengar dan tim radio membentuk realitas subjektif (Tahap14). Kedua, tahap objektivasi tim produksi dan pendengar mengemas realitas simbolik (tahap 5). Ketiga, tahap internalisasi tim radio dan pendengar menetapkan realitas objektif (tahap 6). Intitusionalisasi, legitimasi dan sosialisasi dilakukan melalui enam tahap proses kontruksi tersebut: 1) tahap menerapkan kebijakan karakter SMCRE, 2) tahap memilih ide,fakta, referensi, 3) tahap membuat berbagai skrip, 4) tahap pembentukan realitas subjektif, 5) tahap pengemasan realitas simbolik, dan f) tahap penetapan realitas objektif.

Armawati Arbi memperdalam dan merevisi pandangan Burhan Bungin tentang proses konstruksi media massa atas realitas sosial secara simultan. Namun bedanya, Burhan Bungin fokus pada iklan televisi sebagai tapping (rekaman), bukan produksi siaran langsung (live). Sedangkan Armawati Arbi memproduksi program dakwah dan program live atau konsultasi keluarga siaran langsung.

Rumusan masalah dalam penelitian adalah 1) bagaimana strategi komunikasi Radio Fajri FM dalam mempertahankan citra radio dakwah pada siaran on air 2) bagaimana strategi komunikasi radio Fajri FM dalam mempertahankan citra lembaga radio dakwah pada kegiatan off air.

\section{B. Metode Penelitian}

Penelitian ini menggunakan pendekatan penelitian kualitatif. Penelitian kualitatif adalah metode penelitian yang berlandaskan pada filsafat postpositivisme, digunakan untuk meneliti pada kondisi obyek yang alamiah, di mana peneliti adalah sebagai instrumen kunci, pengambilan sumber data dilakukan secara purposive dan 
snowball, teknik pengumpulan dengan triangulasi, analisis data bersifat induktif, dan hasil penelitian kualitatif lebih menekankan makna daripada generalisasi.

Penelitian ini menggunakan paradigma konstruktivisme. Paradigma ini memandang bahwa kenyataan itu hasil konstruksi atau bentukan dari manusia itu sendiri. Kenyataan itu bersifat ganda, dapat dibentuk, dan merupakan satu keutuhan. Kenyataan ada sebagai hasil bentukan dari kemampuan berpikir seseorang. Pengetahuan hasil bentukan manusia itu tidak bersifat tetap tetapi berkembang terus. Penelitian kualitatif berlandaskan paradigma ini berpandangan bahwa pengetahuan itu bukan hanya merupakan hasil pengalaman terhadap fakta, tetapi juga merupakan hasil konstruksi pemikiran subjek yang diteliti.

Subjek dalam penelitian ini adalah tim produksi Radio Fajri 99,3 FM Bogor dan yang menjadi objek penelitiannya adalah strategi komunikasi dan citra lembaga Radio Fajri 99,3 FM Bogor. Penelitian ini dilaksanakan di Studio Radio Fajri FM, Jalan Raya Kapten Yusuf No. 61, gang Purnama, Desa Sukamantri, Kecamatan Taman Sari, Kabupaten Bogor, Jawa barat, 16610.

Teknik pengumpulan data terdiri dari observasi aktif, wawancara. dan dokumentasi. Sedangkan analisis data adalah proses mencari dan menyusun secara sistematis data yang diperoleh dari hasil wawancara, catatan lapangan, dan dokumentasi dengan cara mengorganisasikan data ke dalam kategori, menjabarkan ke dalam unit-unit, melakukan sintesa, menyusun kedalam pola, memilih mana yang penting dan yang akan dipelajari, dan membuat kesimpulan sehingga mudah dipahami oleh diri sendiri maupun orang lain.

\section{Hasil Dan Pembahasan}

Jumlah kerja sama pada program siaran on-air dapat diungkap. Begitu pula, jumlah kerjasama di off air. Informasi utama untuk pendegar dan juga sebagai menjaring kerjasama untuk perusahaan. Dalam media, tentu selalu ada kaitannya dengan kerjasama demi memajukan suatu radio dalam memberi warna siarannya. Kerjasama dengan radio untuk siaran on air terdapat dua penawaran, melalui jumlah pendengar, iklan dan kemasan program. 
Teori yang berhubungan dengan rumusan masalah ini adalah teori konstruksi media massa. Konstruksi sosial atas realitas sosial dibangun secara simultan melalui tiga proses yaitu eksternalisasi, objektivasi dan internalisasi. Kemudian dilakukan tahap proses kontruksi pada tahap kedua yakni tahap memilih ide, referensi. Dalam tahap kedua ini penyiar membingkai fakta pendengar. Hasil dari tahap memilih referensi adalah jumlah referensi dan jumlah kerjasama. Kemudian ditemukan citra radio dakwah.

Penyiar sebagai komunikator atau penyampai pesan di radio. Penyiar sebagai salah satu faktor menarik minat pendengar untuk mendengarkan siarannya. Radio Fajri FM memiliki 48 ribuan pendengar pada 31 oktober 2018. Berdasarkan hasil wawancara yang telah dilakukan dengan beberapa responden ditemukan bahwa Radio Fajri FM memiliki 48 ribu pendegar dengan rentang waktu pendataan 2012 sampai 31 Oktober 2018. Rata-rata pertambahan pendengar pertahunnya sekitar 7000 sampai 8000 pendengar. Untuk mengetahui jumlah pendengar, tentu mempunyai 2 strategi yakni melalui registrasi pendengar secara langsung dan kedua dari registrasi pendengar baru yang mengikuti acara on air.

Dengan memiliki pendengar yang jumlahnya tidak sedikit, tentu Radio Fajri FM berupaya untuk terus memperbaiki siarannya dengan cara mengadakan evaluasi setiap bulannya. Hal ini disampaikan melalui hasil wawancara sebagai berikut:

"kalau evaluasi itu sebulan sekali. Bukan Cuma membahas masalah program saja, tapi keseluruhan, dari mulai peningkatan jumlah pendengar, interaksi pendengar, publikasi, durasi siaran, kajian fokus, biaya kerja, peta pendengar, kendala, solusi juga diminta. Kalo dari program, untuk perubahan rubrik itu belum banyak bahasan mba. Lebih banyak bahas acara live. Lebih banyak ke peningkatan pendengar, ada bahasan upgrading juga, jadi dengan acara yang ada saat ini bagaimana caranya pembawaannya lebih menarik gitu."

Berdasarkan dari hasil wawancara tersebut, Radio Fajri FM dalam evaluasi program lebih banyak membahas mengenai peningkatan program agar pembawaannya lebih menarik. Dari sini terlihat bahwa peran penyiar amatlah penting dalam peningkatan jumlah pendengar. Maka dari itu Radio Fajri FM 
memiliki kriteria dalam memilih penyiar. Hal ini disampaikan melalui hasil wawancara sebagai berikut:

"Kriteria penyiar Fajri FM adalah laki-laki muslim, memiliki wawasan keislaman, memiliki skill atau kemampuan siaran, dan punya semangat dakwah dan semangat untuk menyuarakan kebangkitan Islam. Klo di Fajri itu gak ada yang kerjanya khusus siaran. Ibaratnya siaran itu kayak sampingan aja. Kaya semacam tugas tambahan saja. Masing-masing punya post kerja, klo siaran tambahan saja. Misal, designer kerjanya kan pahamlah, dia juga ada jadwal siaran, yang bagian marketing juga ada jadwal siaran. Syarat penyiar radio Fajri, ya orangnya kerja di Fajri mba, gak bisa orang luar mau jadi penyiar fajri. Klo dia kerja di Fajri, kemungkinan jadi penyiar, tapi ga ada lowongan khusus penyiar."

Dalam kutipan wawancara tersebut dapat disimpulkan bahwa Radio Fajri FM memiliki kriteria penyiar yakni laki-laki muslim, memiliki wawasan keislaman, memiliki skill siaran, mempunyai semangat dakwah dan hal yang terpenting adalah penyiar Radio Fajri FM merupakan orang yang bekerja di Radio Fajri FM. Jika bekerja di Radio Fajri FM otomatis berkecimpung juga sebagai penyiar namun diperlukan pelatihan terlebih dahulu.

Siaran on air Radio Fajri FM dapat dinikmati melalui jaringan FM dengan frekuensi 99,3 atau streaming di aplikasi android dan di website www.fajrifm.com. Radio Fajri FM memiliki sosial media agar seluruh lapisan masyarakat dapat mengetahui Radio Fajri FM. Berikut adalah kutipan hasil wawancara mengenai upaya yang dilakukan agar masyarakat mengetahui Radio Fajri FM.

"Fajri FM menyiarkan dakwah 24 jam perharinya. Upaya yang saat ini dilakukan agar masyarakat tahu keberadaan Fajri FM adalah dengan menggencarkan dan memasivkan kegiatan publikasi, baik itu melalui Facebook Ads dan Instagram Ads, maupun publikasi langsung dengan cara menempelkan stiker-stiker di kendaraan umum/pribadi, menyebarkan brosur poster dakwah dll."

Siaran menjadi kegiatan utama dalam penyiaran radio. Tentu hal ini tidak lepas dari kerjasama antara radio dengan pihak lain. Dalam wawancara yang telah dilakukan,ditemukan bahwa dalam pembuatan atau memproduksi konten acara 
Radio Fajri FM bekerja sama dengan Mitra Radio. Mitra Radio merupakan sebuah lembaga yang memproduksi konten-konten secara islami.

Berdasarkan dari temuan di atas, terbentuklah proses eksternalisasi yang dilakukan oleh Radio Fajri FM. Proses ekstenalisasi adalah tahap ekstenalisasi pendengar dan tim radio membentuk realitas subjektif. Dengan kata lain proses eksternalisasi dapat dilihat melalui interaksi antara pendengar dengan tim radio. Radio Fajri FM untuk mengetahui jumlah pendengar melalui hasil interaksi dengan pendengar yang setiap tahunnya mengalami peningkatan. Kemudian pendengar dapat berpartisipasi memberikan pesan pada program live melalui media sosial, SMS dan juga telpon tentu sangat memudahkan pendengar untuk berinteraksi dengan tim radio.

Berdasarkan data dokumentasi dari jadwal siaran Radio Fajri FM, terdapat 32 acara tapping dan 7 siaran live. Program Siaran live adalah Program yang menjadi produk yang disajikan dalam radio. Program tentu dapat memanjakan telinga pendengar dengan segala informasi yang diberikan. Program menjadi bentuk dari proses objektivasi dimana pada tahap objektivasi tim produksi dan pendengar mengemas realitas simbolik. Berdasarkan hasil penelitian diketahui ada 7 program live di Radio Fajri antara lain Bunayyati Unjuk Gigi, Talkshow Interaktif, Senada (Seputar Nasihat Anda), Pilda (Materi Pilihan Anda), KITA (Kiat Insan Bertakwa), GAMIS (Gaya Muda Islami) dan Ibroh.

Berdasarkan data wawancara tersebut, terdapat 7 program live yang disiarkan oleh Radio Fajri FM. Berdasarkan pada gambar di atas, pada saat acara live berlangsung, masyarakat dapat berpartisipasi melalui pesan singkat (SMS), Whats App dan Telegram ke nomor 08111110 993, melalui Facebook RadioFajri dan juga melalui telepon ke nomor 02518485444.

Program acara live tersebut ada yang mendatangkan bintang tamu atau narasumber yaitu acara Talkshow Interaktif yang tayang setiap hari senin-jum'at jam 10.00-11.00 WIB. bintang tamu acara Talkshow Interaktif biasanya dari lembaga rekanan radio Fajri, diantaranya YALIFA (Yayasan peduli fajri), Yayasan islam al huda, MPJ (markaz pengurusan jenazah), Mizar (minyak zaitun ruqyah), dll. Menghadirkan juga dari kalangan ahli medis seperti RS UMMI yang rutin 
menjadi bintang tamu sebulan $2 \mathrm{x}$ tiap hari kamis pekan 1 dan 3. Dinas kesehatan kota Bogor sebulan sekali di hari selasa pekan ke-4. Untuk teknis mendatangkan narasumber, tentu Radio Fajri FM membatasi narasumber yang ingin bekerjasama. Dalam hasil wawancara tersebut dapat ditemukan bahwa narasumber yang dapat masuk dalam acara Talkshow Interaktif adalah lembaga rekanan Radio Fajri FM dan kesehatan. Feedback yang didapat antara kedua belah pihak dari radio ke narasumber atau sebaliknya, itu sudah diatur melalui perjanjian atau MoU.

Untuk lebih jelasnya dalam melihat lembaga apa saja yang bekerja sama dalam program Talkshow Interaktif di Radio Fajri FM pada bulan Oktober dan November adalah sebagai berikut.

Tabel 2 Kerjasama Radio Fajri FM pada program Interaktif

\begin{tabular}{lll} 
No & Nama Lembaga Kerjasama & $\begin{array}{l}\text { Frekuensi Hadir } \\
\text { pada bulan Oktober }\end{array}$ \\
\hline 1 & Yayasan Islam Al Huda & 2 kali \\
\hline 2 & Yayasan Peduli Fajar Imani & $3 \mathrm{kali}$ \\
\hline 3 & Fajri Umroh & $1 \mathrm{kali}$ \\
\hline 4 & $\begin{array}{l}\text { FOKUS (Forum Komunikasi) } \\
\text { Pendengar Radio Fajri FM }\end{array}$ & $1 \mathrm{kali}$ \\
\hline 5 & $\begin{array}{l}\text { HASMI (Himpunan Ahlusunnah } \\
\text { untuk masyarakat islami peduli) }\end{array}$ & 2 kali \\
\hline 6 & $\begin{array}{l}\text { Markaz Pengurusan Jenazah } \\
\text { (MPJ) }\end{array}$ & 1 kali \\
\hline 7 & Dinas Kesehatan Kota Bogor & 1 kali \\
\hline 8 & RS. Ummi Bogor & - \\
\hline 9 & Devisi Marketing Fajri & 1 kali \\
\hline 10 & Yayasan Huda Cendikia & 2 kali \\
\hline
\end{tabular}

Sumber: hasil penelitian 2018 
Berdasarkan tabel di atas, ditemukan lembaga yang memiliki frekuensi hadir lebih banyak dalam acara Talkshow Interaktif adalah Yayasan Peduli Fajar Imani. Hal ini menunjukan bahwa Yayasan Peduli Fajar Imani memiliki kontribusi sangat besar dengan Radio Fajri FM.

Radio Fajri FM memiliki 7 program live. Satu program sudah diketahui jumlah kerjasamanya yaitu program Talkshow Interaktif untuk program lainnya yang tidak mendatangkan narasumber adalah sebagai berikut disertai jumlah iklan yang diputarkan ketika acara berlangsung yang ditemukan.

Tabel 3: Program Live tanpa mengundang narasumber dan jumlah kerjasama dari pemutaran iklan

\begin{tabular}{lll}
\hline No. & Nama program & Iklan yang diputarkan \\
\hline 1. & PILDA (Materi Pilihan Anda) & -Yayasan Huda Cendikia \\
& 2 Desember 2018 & -Payung Dakwah Fajri \\
& & -Kalender Fajri 2019 \\
& & Total: 3 kerjasama \\
\hline 2. & GAMIS (Gaya Muda Islami) & -Payung Dakwah Fajri \\
& 1 Desember 2018 & - SD IT dan SMP IT Al Hidayah \\
& & -Kalender Fajri 2019 \\
& & Total: 3 kerjasama \\
\hline 3. & SENADA (Seputar Nasihat Anda) & -Hasmi Islamic School \\
& 2 Desember 2018 & -Minyak Zaitun Ruqyah (Mizar) \\
& & -Yayasan Islam Al Huda \\
& & \\
& & Total : 3 kerjasama \\
\hline 4. & KITA (Kiat Insan Bertaqwa) & -Kalender Fajri 2019 \\
& 3 Desember 2018 & -Hasmi Islamic School \\
& & -Huda Cendikia \\
& & Total: 3 kerjasama \\
\hline 5. & Ibroh & -Fajri Umroh \\
\hline
\end{tabular}


5 Desember 2018

-Payung Dakwah Fajri

-Yayasan Islam Al Huda

Total: 3 kerjasama

\begin{tabular}{lll}
\hline 6. & Bunayati Unjuk Gigi & -Huda Cendikia \\
2 Desember 2018 & - SD IT dan SMP IT Al Hidayah \\
& -Kalender Fajri 2019 \\
& Total: 3 kerjasama \\
\hline Jumlah keseluruhan pemutaran iklan & 18 iklan/Kerjasama \\
\hline
\end{tabular}

Sumber: observasi, dokumen, dan wawancara 2018

Berdasarkan tabel di atas ditemukan bahwa program live tanpa bintang tamu memiliki 3 kerjasama dilihat dari 3 macam pemutaran iklan setiap siarannya. Hal ini sama dengan program yang mendatangkan bintang tamu juga memiliki 3 kerjasama. Jadi, semua program live melibatkan 3 kerjasama pada masing-masing programnya dilihat dari iklan yang diputarkan.

Berdasarkan temuan di atas bahwa proses objektivasi yang dilakukan oleh Radio Fajri FM pada program live terlihat sangat menghidupkan nuansa islami mulai dari pembawaan penyiar menggunakan salam, kemudian ketika sedang membahas suatu tema, penyiar atau narasumber selalu memperkuat tema yang dibahas itu dengan ayat al-Qur'an atau Hadist sehingga pendengar mengetahui informasi tidak hanya diterima oleh logika tetapi juga aturannya sudah ada di dalam al-Qur' an dan Sunnah. Hal ini semakin meningkatkan pendengar untuk terus belajar Islam. Dilihat dari segi kerjasama oleh Radio Fajri FM dengan lembaga lain bahwa semua yang ditampilkan atau disiarkan adalah tujuannya satu yaitu dakwah, dakwah itu sangat luas bisa dari segi sosial, kesehatan. Umumnya adalah kegiatan sosial dan kesehatan. Kegiatan sosial itu dapat berupa bantuan untuk umat, kemudian kesehatan juga untuk memberikan informasi kepada masyarakat perlunya menjaga kesehatan.

Untuk program garapan atau tapping memiliki 32 program. proses pembuatan program garapan atau tapping diketahui dari hasil wawancara berikut. 
"Untuk rekaman itu ada 2, 1. Rekaman kajian di masjid, 2. Rekaman di studio. Jadi setiap hari senin, rabu, jum'at pagi itu ada kajian off air buat karyawan di sini, itu direkam, trus ada editing, baru disiarkan di fajri. Klo dulu kajian off air nya senin-jum'at. Yang biasa diputar dirubrik kajian, pagi, sore atau malam. Untuk berita juga ada timnya mba. Cuma berita fajri sumbernya dari ngambil dari web-web terpercaya saja. Berita pagi dan sore, senin-sabtu. Di sini buat rekaman kerjasama dengan mitradio."

Dari hasil wawancara tersebut ditemukan bahwa ada dua cara dalam memproduksi program garapan atau tapping di Radio Fajri FM, yakni pertama, rekaman tersebut berasal dari rekaman kajian di masjid dan rekaman di studio. Ketika kajian sedang berlangsung, kajian tersebut direkam, kemudian melewati proses editing (tahap 4) dan kemudian disiarkan (tahap 5). Kedua, acara rekaman diproduksi oleh Mitra Radio. Mitra Radio merupakan lembaga yang memproduksi konten-konten Islami. Program garapan atau program tapping tersebut disiarkan dengan rentang waktu yang bervariasi antara lima sampai tiga puluh menit tergantung tema acaranya. Berikut list acara garapan atau tapping beserta referensi datanya.

Tabel di bawah ini menunjukkan bahwa kegiatan-kegiatan off-air mendukung program on air. Dalam table ini kita dapat melihat kerjasama dengan penerbit uku, mitra Radio, pendengar setia, dan berbagai masjid.

\section{Tabel 4 Strategi Framing: Kekuatan Ide, Fakta, dan Referensi Pada program tapping di Radio Fajri FM}

\begin{tabular}{|c|c|c|}
\hline No. & Nama program & Referensi data \\
\hline 1. & $\begin{array}{l}\text { Adab Islami } \\
\text { Setiap hari, pukul } 8.00-08.15 \text { WIB dan } \\
\text { 16.45-17.00 WIB ( } 15 \text { menit) }\end{array}$ & $\begin{array}{l}\text {-Buku } \\
\text {-website }\end{array}$ \\
\hline 2. & $\begin{array}{l}\text { Aqidah } \\
\text { Setiap senin-sabtu pukul 08.15-08.30 } \\
\text { WIB } \\
\text { Setiap hari pukul } 14.50-15.05 \text { WIB (15 } \\
\text { menit. }\end{array}$ & $\begin{array}{l}\text {-Buku } \\
\text {-website }\end{array}$ \\
\hline 3. & Diari (dialog ringan) & $\begin{array}{l}\text {-Buku } \\
\text {-website }\end{array}$ \\
\hline
\end{tabular}




\begin{tabular}{|c|c|c|}
\hline & $\begin{array}{l}\text { Setiap sabtu, pukul 12.55-13.00 WIB dan } \\
\text { pukul 22.00-22.05 WIB ( } 5 \text { menit) }\end{array}$ & \\
\hline 4. & $\begin{array}{l}\text { Doa dan Dzikir } \\
\text { Setiap hari. Pukul 06.35-06.45 WIB (10 } \\
\text { menit) }\end{array}$ & $\begin{array}{l}\text {-Buku } \\
\text { - website }\end{array}$ \\
\hline 5. & $\begin{array}{l}\text { Ensiklopedi Islam } \\
\text { Pagi: Setiap hari, pukul 07.10-07.20 WIB } \\
(10 \text { menit) } \\
\text { sore : } 14.05-14.20 \text { WIB (15 menit) }\end{array}$ & $\begin{array}{l}\text {-Buku } \\
\text {-Website }\end{array}$ \\
\hline 6. & $\begin{array}{l}\text { Fatawa (fatwa-fatwa } \\
\text { keislaman) } \\
\text { Setiap hari, pukul 17.10-17.20 WIB (10 } \\
\text { menit) }\end{array}$ & $\begin{array}{l}\text { e-book atau buku tentang } \\
\text { fatwa dari dalam dan luai } \\
\text { negeri. }\end{array}$ \\
\hline 7. & $\begin{array}{l}\text { Fikih Islam } \\
\text { Setiap senin-sabtu pukul } 07.20-07.30 \\
\text { WIB (10 menit) }\end{array}$ & $\begin{array}{l}\text {-Buku } \\
\text {-website }\end{array}$ \\
\hline 8. & $\begin{array}{l}\text { Fikih Muamalah } \\
\text { Setiap minggu pukul } 06.45-06.55 \text { WIB } \\
\text { (10 menit) }\end{array}$ & $\begin{array}{l}\text {-Buku } \\
\text {-website }\end{array}$ \\
\hline 9. & $\begin{array}{l}\text { Inspirasi Kita } \\
\text { Setiap hari, pukul } 06.55-07.00 \text { WIB dan } \\
21.40-21.45 \text { WIB ( } 5 \text { menit) }\end{array}$ & $\begin{array}{l}\text {-Buku } \\
\text {-Website }\end{array}$ \\
\hline 10. & $\begin{array}{l}\text { Islamul Yaum } \\
\text { Senin-sabtu, pukul 06.45-07.00 WIB (15 } \\
\text { menit) } \\
\text { Senin-sabtu, pukul 17.00-17.10 WIB (10 } \\
\text { menit) }\end{array}$ & $\begin{array}{l}\text { Website berita } \\
\text { terpercaya }\end{array}$ \\
\hline 11. & $\begin{array}{l}\text { Jendela Akhirat } \\
\text { Setiap malam, pukul } 21.30-22.00 \text { WIB } \\
\text { (30 menit) }\end{array}$ & $\begin{array}{l}\text {-Buku } \\
\text {-website }\end{array}$ \\
\hline 12. & $\begin{array}{l}\text { Kuliah Islam } \\
\text { Setiap hari, pukul } 05.30 \text { WIB, } 16.00- \\
16.30 \text { WIB dan } 20.00-21.30 \text { WIB }(30 \\
\text { menit) }\end{array}$ & $\begin{array}{l}\text { Rekaman kajian di masjid Ali } \\
\text { Bin Abi Thalib }\end{array}$ \\
\hline 13. & $\begin{array}{l}\text { Kiat Sehat } \\
\text { Setiap hari, pukul } 09.10-09.15 \text { WIB ( } 5 \\
\text { menit) }\end{array}$ & -Website Kesehatan \\
\hline 14. & $\begin{array}{l}\text { Kisah Anak Sholeh } \\
\text { Setiap minggu, pukul 07.20-07.30 WIB } \\
(10 \text { menit) }\end{array}$ & $\begin{array}{l}\text {-Buku kisah } \\
\text {-website }\end{array}$ \\
\hline
\end{tabular}


15. Kisah Mulia -Buku kisah

Setiap senin-sabtu, pukul 07.40-07.50 - website WIB dan 16.35-16.45 WIB (10 menit)

16. Kisah Taubat -Buku

Setiap hari, pukul 22.15-22.25 WIB (10 -website menit)

17. Mutiara Ayat

Setiap hari, pukul 18.30-18.35 WIB

Alqur'an dan tafsir

Senin-jum'at, pukul 22.00-22.05 WIB

Setiap minggu, pukul 22.00-22.05 WIB

(5 menit)

18. Mutiara Hadist

Buku Hadist dan tafsir

Setiap hari, pukul 11.25-11.30, 18.55-

19.00 dan 22.45-22.50 WIB (5 menit)

19. Mutiara Ilmu -Buku

Setiap hari, pukul 19.50-19.55 WIB (5 -website menit)

20. Mutiara Qur'an

Alqur'an dan tafsir

Setiap hari, pukul 06.10-06.20 dan 19.40-

19.50 WIB (10 menit)

21. Mutiara Sunah -Buku

Senin-sabtu, pukul 09.05-09.10 WIB (5 -website menit)

22. Ngopi (Ngobrol Perkara Iman) -buku

Setiap jum'at dan sabtu, pukul 05.30- -website 06.00 WIB (30 menit)

23. Oase Islam -Website

Setiap minggu, pukul 12.40-13.00 WIB -buku (20 menit)

24. Pemuda Hijrah

-Website

Senin-sabtu, pukul 12.40-12.55 dan -buku 21.45-22.00 WIB (15 menit)

25. Syarah Hadist -Buku hadist

Setiap senin-sabtu, pukul 08.40-08.50 -buku tafsir hadist WIB (10 menit) -website

26. Tafsir Tematik

Setiap hari, pukul 14.40-14.50 WIB -Buku tafsir alqur'an (10 menit)

27. Tahukah Anda Website

Setiap hari, pukul 12.30-12.40 WIB 


\begin{tabular}{|c|c|c|}
\hline \multirow{2}{*}{28.} & \multicolumn{2}{|l|}{ (10 menit) } \\
\hline & $\begin{array}{l}\text { Tarikh islam } \\
\text { Setiap minggu, pukul 21.45-22.00 WIB } \\
\text { (15 menit) }\end{array}$ & Website \\
\hline 29. & $\begin{array}{l}\text { Tilawah Terjemah } \\
\text { Senin-sabtu, pukul 07.30-07.40 WIB (10 } \\
\text { menit) }\end{array}$ & alqur'an terjemah \\
\hline 30. & $\begin{array}{l}\text { Tokoh Islam Nasional } \\
\text { Setiap minggu, pukul } 17.00-17.10 \mathrm{WIB} \\
\text { (10 menit) }\end{array}$ & $\begin{array}{l}\text {-Buku } \\
\text {-website }\end{array}$ \\
\hline 31. & $\begin{array}{l}\text { Wanita Islami } \\
\text { Senin-sabtu, pukul 08.30-08.40 WIB (10 } \\
\text { menit) }\end{array}$ & Website \\
\hline 32. & $\begin{array}{l}\text { Wawasan Islam } \\
\text { Setiap hari, pukul 06.20-06.30 dan 15.05- } \\
\text { 15.15 WIB (10 menit) }\end{array}$ & $\begin{array}{l}\text {-Buku } \\
\text {-website }\end{array}$ \\
\hline & Jumlah referensi & 54 referensi \\
\hline
\end{tabular}

Dari tabel di atas dapat ditemukan dalam mencari ide, fakta, dan berbagai referensi pada tahap 2. Referensi yang digunakan untuk menjadi bahan program tapping adalah buku, website serta al-Qur'an dan hadist. Karena teknologi semakin canggih, mayoritas referensi yang digunakan adalah dengan mengandalkan website. Strategi dalam program rekaman adalah yang pertama adalah pembuatan naskah dari berbagai referensi yang telah disebutkan, kemudian yang kedua dilakukan pengkoreksian naskah oleh ustad, kemudian yang ketiga adalah dilakukannya rekaman dengan pengisi suara, kemudian yang ke empat mengecek quality control audio, dan yang terakhir adalah audio siap untuk disiarkan. (observasi aktif tahap 4 dalam membentuk realitas subjektif, 2018).

Terdapat 32 acara tapping yang disiarkan di Radio Fajri FM. Masingmasing acara memiliki pembahasan yang berbeda. Dengan adanya program tapping ini, siaran dakwah di Radio Fajri FM menjadi penuh dengan akan kajian atau informasi terkait agama Islam. Jika radio lain memutarkan banyak lagu. Sebaliknya, Radio Fajri FM yang tidak memutarkan lagu, justru dengan adanya program tapping ini mengganti lagu-lagu yang biasa diputarkan di radio lain, hal ini menjadi 
salah satu keunikan yang ada pada Radio Fajri FM. Hal ini menunjukkan reputasi, brand, dan citra radio Fajri.Reputasi berkaitan dengan respon orang lain terhadap karakter SMCREnya. Brand berkaitan dengan visi, misi,logo, jingle dan lainnya. Sedangkan citra adalah orang tahu radio Fajri dari temannya atau promosinya melalui old media dan new media.

Berdasarkan hasil temuan di atas, terlihat bahwa terjadi proses objektivasi yang terlihat pada program tapping sebenarnya tidak jauh beda dengan yang terjadi pada program live yakni menghidupkan nuansa Islam. namun bedanya hanya teknis saja. Ketika program tapping diputarkan terdengar sangat berbeda dengan program live. Program tapping ini lebih kepada intisari dari tema, ulasannya berdasarkan alqu'an dan hadist. Tema yang disampaikan langsung kepada intisari karena program tapping ini hanya memiliki waktu yang lebih singkat dibandingkan dengan program live.

Berdasarkan hasil wawancara, acara off air yang diadakan oleh radio Fajri FM adalah sebagai berikut.

"Kegiatan off air mingguan itu ada publikasi seperti brosur, stiker, poster,. Kegiatan off air bulanan ada kajian bulanan FOKUS (Forum Komunikasi Pendengar) Fajri di 4 kota Bogor, Tangerang, Bekasi, dan Depok. Biasanya dilaksanakan di masjid-masjid.dan ada kegiatan off air tahunan yaitu temu pendengar Radio Fajri”

Radio Fajri FM memiliki acara off air bulanan yakni kajian bulanan setiap hari minggu di 4 kota yang berbeda yakni Tangerang, Bekasi, Depok dan Bogor. Acara off air diselenggarakan oleh Forum Komunikasi Pendengar Fajri FM yaitu perkumpulan para pendengar setia Radio Fajri FM yang berada di berbagai kota, yang kemudian bekerja sama dengan Radio Fajri FM dengan memfasilitasi menyediakan ustad pemateri sebagai pembicara pada kajian tersebut. Jadi pada acara off air kajian bulanan ini, Radio Fajri FM hanya menyediakan pembicara, yang mengadakan sebenarnya adalah Fokus Pendengar Radio Fajri FM. Dalam acara ini tentu memiliki daya tarik masyarakat untuk mendengarkan Radio Fajri FM, serta ikut mengikuti sedekah dan menjadi donatur sebagai mendukung 
kegiatan dakwah yang diselenggarakan Radio Fajri FM. Berikut adalah poster kajian bulanan FOKUS Fajri di wilayah Depok, Bogor, Tangerang, dan Bekasi.

Dengan adanya kegiatan kajian bulanan ini, terbentuklah kerjasama antara Radio Fajri FM dengan FOKUS pendengar Fajri FM. Hal ini disampaikan juga dari hasil wawancara sebagai berikut.

"Untuk kegiatan off air Fajri FM, dalam hal ini kajian bulanan bekerjasama dengan Forum Komunikasi Pendengar Radio Fajri (Fokus) dengan menghadirkan pemateri-pemateri dari ustad-ustad Radio Fajri."

Adapun kegiatan off air mingguan yaitu penyebaran media publikasi seperti brosur, stiker, dan poster ke masjid-masjid. Hal ini disampaikan pada kutipan wawancara sebagai berikut.

"kita ngadain kegiatan publikasi, nyebar poster di masjid-masjid, nyebar brosur di tempat-tempat umum, nempel stiker di mobil-mobil sambil dikasih tau keberadaan radio Fajri. Klo desember sih biasanya publikasi via kalender yang 1 lembar. Poster juga macam-macam temanya, ada tentang riba, adab masjid, dll. Untuk penyebarannya baru di bogor, klo luar bogor dibantu FOKUS Fajri."

Untuk acara tahunan, terakhir diadakan pada September 2017. Acara ini berbeda dengan kajian bulanan. Acara tahunan ini lebih megah dan yang mengikuti adalah seluruh pendengar radio Fajri FM di berbagai kota. Hal ini disampaikan dalam wawancara sebagai berikut.

"terakhir ngadain tahun kemarin kalau ga salah, september 2017. Tahun ini belum. Acaranya gede mba, ada bazar juga, kajian, doorprize, yang datang semua pendengar fajri berbagai daerah. Beda dengan kajian bulanan fokus, klo yg bulanan masing-masing kota aja. Saya kembali ke Fajri bulan April, gak ada acara tahunan. Kita rutin acara mingguan sama bulanan aja mba."

Berdasarkan hasil wawancara dan observasi, kegiatan off air radio Fajri FM pada tahun 2018 hanya rutin mengadakan kajian bulanan dan mingguan yang diadakan oleh FOKUS (forum komunikasi pendengar) Fajri FM. Fokus Fajri FM ini tersebar di 4 kota yaitu Tangerang, Bekasi, depok, dan bogor. 
Berdasarkan hasil temuan di atas, ditemukan proses internalisasi dalam pembentukan realitas objektif dimana masyarakat dapat mengikuti acara off air yang diselenggarakan oleh Radio Fajri FM. Proses internalisasi yang dilakukan oleh Radio Fajri FM yakni mengadakan kegiatan off air rutin yang dapat diikuti oleh seluruh lapisan masyarakat. Kegiatan off air yang diadakan oleh Radio Fajri FM terdiri dari kegiatan off air mingguan, bulanan, dan tahunan. Untuk kegiatan off air mingguan, Radio Fajri FM hanya memberikan media publikasi seperti brosur, dan stiker kepada masyarakat. Kemudian untuk kegiatan off air bulanan, Radio Fajri FM mengadakan kajian bulanan setiap hari minggu di 4 kota yakni Tangerang, Bogor, Bekasi dan Depok. Kemudian untuk kegiatan off air tahunan diadakan acara temu pendengar Fajri. Melalui kegiatan off air tersebut, masyarakat dapat lebih mengenal Radio Fajri FM sebagai radio dakwah.

\section{Penutup}

Radio dakwah Fajri bertahan hidup di radio komersil yang berjaring FM karena radio memanfaatkan pendengar setia pada berbagai kegiatan off air. Fakta dari berbagai events itu merupakan strategi framing untuk berbagai tapping programnya. Radio dakwah yang eksis melibatkan pendegar setia, mahasiswa, dan remaja di kalangan masyarakatnya pada pra produksi (tahap 1-4) sebagai strategi framing. Rekaman berbagai events diedit menjadi planning running run down sebagai strategy of priming. Kekuatan tata waktunya dan tata letak promosi di new media dapat menjaring pendengar. Final run down dikemas melalui berbagai metode dakwah dan komunikasi. Akhirnya, banyaknya tapping program dapat menarik pendengar. Banyaknya kerjasama pada program on air dan off air melalui ketiga proses terkait dalam teori konstruksi sosial media massa yang memiliki 3 proses penerapan konstruksi yakni eksternalisasi, obyektivasi dan internalisasi. Radio dakwah mampu bertahan.

Pada proses obyektivasi, Radio Fajri FM memiliki program siaran live dan tapping. Terdapat 7 program live dan 32 program tapping. Ditemukan juga Jumlah kerjasama pada program live adalah 3 total kerjasama pada acara yang mendatangkan narasumber dan 3 total kerjasama pada acara yang tidak 
mendatangkan narasumber. Kerjasama yang dilakukan pada siaran on air terlihat pada pemutaran iklan dan narasumber yang hadir. Jumlah referensi pada program tapping terdiri dari buku, kitab dan web terpercaya adalah 54 referensi dari 32 acara tapping. Kemudian setelah mendapatkan referensi, dilakukan pengoreksian terhadap ustad sebagai kontrol khusus pada program tapping yang membahas keislaman agar tidak keluar konteks keislaman yang ada.

Pada proses internalisasi ditemukan bahwa Radio Fajri FM memiliki kegiatan off air mingguan, bulanan, dan tahunan. Kegiatan off air mingguan yakni menyebarkan media publikasi seperti stiker, poster, dan juga brosur terkait Radio Fajri FM. Kemudian untuk kegiatan off air bulanan yaitu mengadakan kajian bulanan diberbagai kota yakni Bogor, Depok, Tangerang, dan Bekasi. Untuk kegiatan off air tahunan, adanya kegiatan temu pendengar Fajri dari berbagai wilayah. Jumlah kerjasama yang ditemukan di off air dalam mempertahankan citra melalui strategi penyebaran poster digital ke media sosial dengan mencantumkan sponsor atau lembaga kerjasama di bawahnya.

\section{Referensi}

Alhadharah. (2015). Efektifitas Komunikasi Dakwah Melalui Radio. Jurnal Ilmu Dakwah Vol. 14 No. 27.

Anggoro, M. Linggar. (2005). Teori dan Profesi Kehumasan: Serta Aplikasinya di Indonesia. Jakarta: PT. Bumi Aksara.

Arbi, Armawati. (2012). Konstruksi Sosial Media Massa Radio Dangdut Jakarta Atas Realitas Problem Keluarga. Disertasi.

Arifin, Anwar. (1984). Strategi komunikasi. Bandung: Armilo.

Arifin, Zainal. (2012). Penelitian pendidikan Metode dan Paradigma Baru. Bandung: Rosdakarya.

Astuti, Santi Ira. (2010). Jurnalisme Radio Teori dan Praktek. Jakarta: Simbiosa Rekatama Media. 
Bajari, Atwar. (2015). Metode Penelitian Komunikasi. Bandung: Simbiosa Rekatama Media.

Bungin, Burhan. (2011). Konstruksi Sosial Media Massa: Kekuatan Pengaruh Media Massa, Iklan Televisi, dan Keptusan Konsumen Serta Kritik Terhadap Petter L. Berger \& Thomas Luckmann. Jakarta: Kencana Prenada Media Group.

Bungin, Burhan. (2014). Sosiologi Komunikasi: Teori, Paradigma, dan Diskursus Teknologi Komunikasi di Masyarakat Edisi Pertama. Jakarta: Kencana Prenada Media Group.

Darwanto. (1994). Produksi Acara Televisi. Yogyakarta: Duta Wacana University pers.

Departemen Pendidikan dan Kebudayaan Republik Indonesia. (1990). Kamus Besar Bahasa Indonesia. Jakarta: Balai Pustaka.

Departemen Pendidikan Nasional RI. (1997). Kamus Besar Bahasa Indonesia. Jakarta: Balai Pustaka. cet ke-9.

Djuroto, Totok. (2007). Mengelola Radio Siaran. Semarang: Dahara Prize. Effendi, Onong Uchana. (1991). Radio Siaran Teori dan Praktek. Bandung: Mandar Maju.

Effendy, Onong Uchjana. (2008).Dinamika Komunikasi. Bandung: PT Remaja Rosdakarya.

Ghozali, M. Bahri. (1997). Dakwah Komunikatif: Membangun Kerangka Dasar Ilmu Komunikasi Dakwah. Jakarta: Pedoman Ilmu Jaya.

Hamad, Ibnu. (2010). Komunikasi Sebagai Wacana. Jakarta: LaTofi Enterprise. edisi Pertama.

Jefkins, Frank. (2003). Public Relations: Edisi Kelima. Jakarta: Erlangga.

Kusnawan, Aep. (2004). Komunikasi Dan Penyiaran Islam. Bandung: Benang Merah Press. 
Masduki. (2004). Menjadi Broadcaster Profesional. Yogyakarta: Pustaka Populer LkiS.

Masy'ari, Anwar. (1981). Studi Tentang Ilmu Dakwah. Surabaya:Bina Ilmu.

Morissan. (2015). Manajemen Media Penyiaran: Strategi Mengelola Radio dan Televisi. Jakarta: Prenadamedia Group.

Morissan. (2015). Teori Komunikasi: Individu Hingga Massa. Jakarta: Prenadamedia Group.

Munthe, Muryanto Ginting. (1996). Media Komunikasi Radio. Kumpulan Karangan, Jakarta Pusat Sinar Harapan. cet. 1.

Musfiqon. (2012). Panduan Lengkap Metodologi Penelitian Pendidikan. Jakarta: Prestasi Pustaka Publisher.

Prayudha, Harley. (2006). Radio: Penyiar It's not Just a Talk. Jawa Timur: Bayumedia Publishing.

Purnomo, Setiawan Hari. (1996). Manajemen Strategi: Sebuah Konsep Pengantar. Jakarta: Fakultas Ekonomi Universitas Indonesia.

Romli, Asep Syamsul M. (2004) Broadcast Journalism: Panduan Menjadi Penyiar, Reporter \& Script Writer. Bandung: Nuansa.

Soekanto, Soerjono. (1993). Kamus Sosiologi. Jakarta: PT Raja Grafindo Persada.

Soemirat, Soleh dan Ardianto, Elvinaro. (2010). Dasar-Dasar Public Relation. Bandung: Remaja Rosdakarya.

Sugiyono. (2015). Metode Penelitian Pendidikan: Pendekatan Kuantitatif, Kualitatif dan $R \& D$. Bandung: Penerbit Alfabeta.

Syihata, Abdullah. (1986). Da'wah Islamiyah. Jakarta: Departemen Agama.

Wahyudi, J.B. (1992). Teknologi Informasi dan Produksi Citra Bergerak. Jakarta: PT. Gramedia Pustaka Utama. Cet. 1.

\section{Laporan wawancara}

Marino, B. (2014, 18 Octobers). Personal Interview. 
Ridwan Farid, S.H.I., M.M. sebagai Direktur Radio Fajri 99,3 FM Bogor. (2018, 26 November)

Dwiky Apriansyah, S.Ud. sebagai Divisi Program radio Fajri 99,3 FM Bogor. (2018, 26 November)

Haristian Sahroni Putra, S.Pd. sebagai Sekretaris dan Humas radio Fajri 99,3 FM Bogor . (2018, 26 November) 
Al-Munzir Vol. 13. No. 2 November 2020 